\title{
TELHADO VERDE E ECONOMIA DE ENERGIA
}

\section{Cleber Rodrigues}

Graduando em Engenharia Civil pelo Centro Universitário Augusto Motta (UNISUAM), RJ, Brasil engcleberprof@bol.com

\section{José Roberto Moreira Ribeiro Gonçalves}

Mestre em Engenharia Agrícola e Ambiental pela UFRRJ, RJ, Brasil

Professor do Centro Universitário Augusto Motta (UNISUAM), Rio de Janeiro, RJ, Brasil joserobertoverde@gmail.com

\section{RESUMO}

O presente artigo foi realizado com o objetivo de identificar e apresentar vantagens relacionadas à utilização do telhado verde como forma de fomentar a redução do consumo de energia elétrica, apresentando seus benefícios para áreas urbanas e sua contribuição para o desenvolvimento sustentável. Para tentar encontrar essas vantagens, foram coletadas informações em trabalhos realizados e publicados por acadêmicos e pesquisadores e pesquisas em Empresas que executam serviços com o telhado verde, a fim de verificar se realmente há a possibilidade dessa redução e também sua viabilidade econômica.

PALAVRAS-CHAVES: Telhado Verde. Consumo. Energia Elétrica. Sustentabilidade.

\section{ABSTRACT}

This article was conducted with the objective of identifying and presenting advantages related to use of the green roof as a way to foster the reduction of electricity consumption, presenting its benefits to urban areas and their contribution to sustainable devel- 
opment. To try to find these advantages, we collected information on work carried out and published by academic research on companies running services with the green roof, in order to verify that there really is the possibility of this reduction and also its economic viability.

KEYWORDS: Green Roof. Consumption. Electric Energy. Sustainability.

\section{INTRODUÇÃO}

Nos últimos anos, tem-se presenciado um aumento significativo de escassez de água, devido à forte estiagem que assola a região centro-sul do Brasil, isso tem ocasionado o racionamento de água e elevado os preços das tarifas das contas de luz. Muito se tem falado em soluções para esse problema, mas pouco se tem feito de fato. Uma das possibilidades de muitas ações que podem ser feitas para diminuir esse consumo de energia elétrica e ajudar na preservação ambiental é o uso do telhado verde, com a finalidade de reduzir o consumo de energia elétrica gasto para conforto ambiental nas edificações, o que levanta questionamentos sobre a utilidade e eficácia. É necessário um estudo para saber se o seu emprego reduzirá o consumo de energia e as consequências negativas para o meio ambiente. Talvez isso possa ser alcançado se houver uma redução de calor por meio da utilização do telhado verde.

O objetivo deste artigo foi verificar as viabilidades socioeconômicas e ambientais para a sociedade brasileira com o emprego do telhado verde.

Tem-se como foco analisar dados e valores para comparar essas viabilidades por meio da redução do consumo de energia elétrica, seus benefícios e custos, associado ao uso do telhado verde.

Por intermédio de uma pesquisa do tipo descritiva, bibliográfica, com análise de dados, procura-se compreender se há, ou não, a possibilidade da redução do consumo de energia elétrica. 


\section{TELHADO VERDE}

Trata-se de um projeto arquitetônico, feito de solo e vegetação, geralmente em uma cobertura impermeabilizada, em lajes de residências, de fábricas, de edifícios comerciais e de shoppings, com a finalidade de melhoramento estético, drenagem de água da chuva para reuso, redução de consumo de energia elétrica e conforto térmico do ambiente (TOMAZ, 2008).

"Geralmente são aplicados em telhados praticamente planos com inclinação aproximadamente de 5o para permitir o escoamento não muito rápido da água. Para telhados acima de 20 ㅇ deverão ser tomadas outras providências para deter o fluxo de água como barreiras ou outras estruturas" (TOMAZ, 2008).

A importância desse tema é descrita por Carneiro, Guiselini, et al., (p. 1086, 2015), com o intuito de avaliar o conforto térmico proporcionado por diferentes tipos de cobertura, com base nas análises térmicas e nos índices de conforto térmico humano e zootécnico.

Também foi verificada a importância do assunto, na dissertação de Oliveira (2009). Esse projeto utilizou uma tecnologia adaptada dos telhados verdes para edificação popular (telhado de fibrocimento), com o objetivo de verificar aspectos construtivos, possíveis espécies com potencial de geração de renda, custos, efeitos no retardo do escoamento superficial das águas pluviais e outros benefícios associados a questões climáticas locais e de conforto do ambiente interno.

Costa, et al., (2015) realizaram uma pesquisa, com o objetivo de realizar análise comparativa entre as temperaturas interna e externa de casas de telhado com cobertura verde e as de telha convencional, visando à economia de energia para resfriamento e menor impacto ambiental.

Propõe-se que a utilização do telhado verde em edificações contribui para a diminuição do gasto com energia elétrica. Para estudar se de fato isto ocorre, é necessário parametrizar dados importantes e analisá-los da seguinte forma: (COSTA, et. al., 2015)

a) Características da edificação: 
Tem grande importância a localização geográfica da edificação devido às peculiaridades do clima (como umidade, insolação e índice pluviométrico); a orientação da edificação aberturas das janelas, o grau de inclinação do telhado da edificação e o custo de construção de cada tipo de edificação.

b) Conforto térmico:

Interage com as características da edificação e do ser humano. Trata-se de como o corpo humano se comporta perante as temperaturas e percebe isso de forma confortável ou desconfortável.

Condição ambiental:

É um dos itens que mais diretamente influencia no gasto de energia. É preciso conhecer até onde o telhado verde é capaz de trazer o conforto térmico, antes que medidas complementares sejam acionadas para atingi-lo. (COSTA, et. al., 2015)

Estes parâmetros irão compor a base para avaliar se o telhado verde é efetivamente uma alternativa para a redução do consumo de energia elétrica e em que medida (COSTA, et. al., 2015).

2.1 Um breve histórico sobre telhado verde

Com a desenfreada urbanização, as áreas verdes estão ficando cada vez menores, surgindo, assim, ilhas de calor, poluições ambientais, enchentes e chuva ácida. Com isso, novas técnicas, inovações e ações de sustentabilidade surgem. A mais recente inovação conhecida é o telhado verde, também telhado vivo, telhado ecológico, biocobertura ou outros nomes que se apresentam (BENETTI, 2013).

O telhado verde parece ser algo novo, mas é bem mais antigo que se possa imaginar, tendo sido inicialmente concebido com um objetivo estético. $O$ registro mais antigo do seu emprego remonta ao Jardim Suspenso da Babilônia, onde se usavam vegetação acima das construções (ECOCIDADES, 2019).

Na cidade de Nova York (EUA), mais precisamente no bairro do Brooklin, que é 
considerado o bairro mais sustentável do mundo, por suas chamadas "hortas urbanas" (telhados verdes produtivos), que produzem, anualmente, toneladas de hortaliças e de vegetais, está sendo construído o maior telhado verde do mundo. Ele está sendo construído sobre a cobertura do antigo Armazém da Marinha dos Estados Unidos e terá 9,3 mil $\mathrm{m}^{2}$, o equivalente a dois campos de futebol no tamanho padrão da FIFA (Federação Internacional de Futebol) (ECOTELHADO, 2013).

No Brasil, o primeiro telhado verde foi implantado no Palácio Gustavo Capanema - sendo atualmente a sede do Ministério da Educação -, no Rio de Janeiro em 1947, pelo arquiteto Lucio Costa (CANERO e REDONDO, 2010).

Podemos dividir em três tipos de coberturas verdes: a extensiva, a semi-extensiva e a intensiva. Ambas oferecem benefícios, mas antes devemos decidir qual a cobertura verde desejada, o custo mais correspondente com o desejado (pois há diferença no custo de manutenção), seleção de plantas, substratos e a estrutura que suporta as sobrecargas da cobertura (ARQUITETURA E SUSTENTABILIDADE, 2012).

Decorrente do aumento da demanda de energia nas grandes cidades, há uma maior procura por materiais do tipo isolantes térmicos, tanto em regiões de clima quente, quanto em regiões de clima frio. O projeto térmico de edifícios urbanos depende da exigência térmica requerida das condições climáticas externas e dos materiais de construções utilizados nas respectivas vedações, pois os raios emitidos pelo sol exercem grande influência nas estruturas dos edifícios, principalmente quando não possuem uma proteção térmica adequada (RIVERO, 1998; ARAÚJO, 2007).

Também, em função da importância da vegetação no meio urbano, os telhados verdes tornam-se uma tendência, contribuindo para a redução dos níveis de dióxido de carbono (CO2) produzido pelos veículos, indústrias e sistemas mecânicos (NIACHOU, 2001; ARAÚJO, 2007).

De acordo com Sainz, et al., (2006), os telhados verdes estão entre as várias tecnologias para o desenvolvimento de mais edifícios ambientalmente sustentáveis e para a criação de ambientes urbanos visualmente atraentes. Assim, são geralmente construídos para melhorar a eficiência energética de um edifício e com diversos benefícios, incluindo o aumento da retenção de água, contribuindo para reaproveitamento e drenagem das 
águas pluviais, a redução da ilha de calor urbana, a redução da concentração de $\mathrm{CO} 2$, a absorção acústica, o melhoramento estético das cidades, o aumento da biodiversidade e a redução da perda de habitat (KOSAREO, 207; BIANCHINI, 2012).

A classificação do telhado vivo depende do peso que cada um realiza sobre a estrutura. Desse modo, há duas classificações: o telhado extensivo - mais leve - e o intensivo - mais pesado (HENEINE, 2008). O telhado extensivo dispõe de plantas de pequeno porte, exigindo uma rasteira camada de solo - de 5 a $15 \mathrm{~cm}$ de espessura. Este tipo acrescenta à carga do telhado da casa de 70 a $170 \mathrm{~kg} / \mathrm{m}^{2}$. Normalmente as plantas que o compõe são gramíneas e aromáticas que não carecem de manutenção frequente (HENEINE, 2008; STRAPASSON, 2010).

Já o telhado intensivo é composto por plantas de grande porte, o que exige uma camada de solo mais profunda - acima de $15 \mathrm{~cm}$. Como ela aplica maior peso sobre a estrutura - entre 290 a $970 \mathrm{~kg} / \mathrm{m}^{2}$-, necessita de atenção redobrada na hora da realização do projeto. As plantas que o compõe são, na maioria das vezes, árvores de porte médio e arbustos, como por exemplo, Cebolinha-de-jardim, Capim-chorão, Cacto-margarida, Cambará e Grama-batatais; portanto o cuidado deverá ser realizado periodicamente (D’AVILA, 2010; HENEINE, 2008; STRAPASSON, 2010).

Nos anos 70, organizações privadas, universidades e centros de pesquisa realizaram estudos envolvendo o telhado verde, a fim de verificar suas aplicações em melhorias no desempenho de sistema de drenagem e de impermeabilização, balanço energético e conforto ambiental. Esses estudos contribuíram para a possibilidade de seu emprego e foi verificado como sendo uma excelente ferramenta para o desenvolvimento sustentável em áreas urbanas. Atualmente, em várias cidades da Europa e também no Brasil, vem sendo empregado o telhado verde visando quantificar a sua atuação na diminuição do escoamento superficial da água de chuva e no combate às ilhas de calor urbanas (RODRIGUEZ, 2006).

\section{METODOLOGIA}

Para o estudo da efetividade da redução dos custos com energia elétrica, com 
ventilação e com refrigeração, devido à utilização do telhado verde pela hipotética redução da temperatura ambiente interna em uma edificação, foi realizada uma pesquisa bibliográfica sobre os trabalhos e projetos feitos ao longo dos anos por universidades e por empresas.

O material obtido para a realização do estudo é proveniente de artigos em revistas, periódicos, teses, dissertações, acervos digitais do portal da Coordenação de Aperfeiçoamento de Pessoal de Nível Superior (CAPES).

Diferentes estudos abordaram aspectos variados da utilização do telhado verde em edificações, como a capacidade de retenção e o retardo do escoamento de água da chuva, e amenização dos efeitos das ilhas de calor nas cidades, o isolamento acústico, o sequestro de carbono, o apelo decorativo, a diminuição da amplitude térmica nas edificações e a melhoria no conforto térmico. O foco deste trabalho está na aplicação do telhado verde como forma de economia de energia elétrica, seja pela diminuição do consumo direto, que se dá ao se deixar de usar algum equipamento para resfriar o ambiente da edificação, ou pelo consumo indireto, através do reuso da água da chuva tanto para cultivo, quanto para serviços diversos em que não seja necessário o uso de água potável (isso permite que menos água seja consumida da distribuidora).

Foram observados os estudos que atenderam ao mesmo objeto deste trabalho e discutidos os seus resultados a fim de avaliar se nosso questionamento inicial sobre as vantagens foi satisfatoriamente respondido.

Nota-se que os estudos utilizam princípios semelhantes de obtenção e análise dos dados, ou seja, a construção que utiliza o telhado verde é comparada com o telhado convencional e verificado o seu desempenho. A partir deste ponto é discutida a viabilidade de utilizar o telhado verde como forma de economia de energia levando em conta o seu custo de construção.

\section{RESULTADOS}

Como esperado, o custo para adquirir os insumos e para a instalação é superior 
ao empregado, porque é necessário um material além daquele utilizado para se construir um telhado convencional e uma mão de obra mais especializada para realizar o serviço de instalação. Porém, os ganhos são interessantes do ponto de vista econômico e arquitetônico, visto que a edificação fica protegida da insolação, o que evita grandes variações de temperatura (fator que contribui para a dilatação e contração da laje, com consequente geração de trincas ou rachaduras), mesmo sendo necessário realizar pequenas manutenções periodicamente.

Em experimento feito por Lopes (2007), foram comparados com a temperatura ambiente de $34^{\circ} \mathrm{C}$ os modelos de telhado verde, de fibrocimento e cerâmico para uma tomada de temperatura simultânea durante o dia. Seus resultados foram 26.5 으, 29.7 으 e 30.6 ㄷ , respectivamente. O autor declara que encontrou uma redução da diferença entre a maior e menor temperatura medida durante o dia da ordem de 50\%, comparado com o ambiente externo, ou seja, ao longo do dia a temperatura não varia muito se comparada com uma construção de telhado convencional. Isso acaba por se traduzir em conforto térmico interno e em menos demanda de energia elétrica para os aparelhos de condicionamento, sejam ventiladores ou ares-condicionados.

Estudo com abordagem semelhante, feito por Araújo (2007), demonstrou que a origem de tal melhoria de desempenho em economia de energia se deve pela concepção do telhado verde. Sua construção faz com que a vegetação receba o calor do sol; uma parte é utilizada para a fotossíntese, a outra é transmitida para o solo, depois passa por radiação para o ar entre o telhado verde e a laje (visto que há espaço livre para a drenagem, e se contiver água armazenada irá absorver adicional parcela do calor) e, por último, para a laje. Isto causa um retardamento da transmissão de calor. $O$ efeito contrário também é verdade, ou seja, o ambiente é mantido com a sua temperatura durante a noite num decair mais lento.

Estudo sobre eficiência energética feito por Baldessar (2012) mostrou que de fato o uso do telhado verde pode ser muito interessante para o nosso país do ponto de vista da economia de energia, pois cerca de $44.98 \%$ da energia consumida são gastas em residências que possuem telhado convencional. Esse impacto positivo se estende para economia de água, uma vez que o sistema de geração hidroelétrico será menos exigido.

A absorção da água das chuvas é outra vantagem, pois o telhado absorve boa 
parte da água das chuvas; se coletada e tratada para o uso doméstico, podendo ser usada para a irrigação de jardins, descargas sanitárias e lavagens de calçadas, por exemplo (WILLES, 2014), constituindo-se em prática sustentável, pela economia de água.

Na construção do telhado verde, uma das partes mais cruciais é a escolha da vegetação a ser usada. A vegetação escolhida deve ser de fácil manutenção, para manter o telhado sempre bem tratado. As plantas devem ser resistentes ao sol e ao vento comparado às condições climáticas do local onde está a construção (PENSAMENTO VERDE, 2013).

Os custos da aplicação do telhado verde variam consideravelmente de acordo com o sistema adotado e com a mão de obra disponível no mercado de trabalho, porém, existem empresas que comercializam módulos que facilitam a implantação da cobertura verde e tornam a escolha economicamente viável (ECOEFICIENTES, 2013, p. 1).

A relação dos benefícios decorrentes da adoção de telhados verdes em áreas urbanas vai dos aspectos de conforto térmico predial e micro-clima local ao controle do escoamento de águas superficiais e é descrito em diversos trabalhos na literatura (BASS et al., 2000), apud (FERREIRA; et al., 2007). 
Tabela 1 - Apresenta comparação entre telhados verdes e telhados convencionais, relacionando diferentes parâmetros climáticos, hidrológicos, financeiros, entre outros, a partir da experiência da cidade de Portland-EUA

\begin{tabular}{|c|c|c|}
\hline Assunto & Telhado Verde & Convencional \\
\hline \multicolumn{3}{|l|}{ Água de Chuva } \\
\hline Retenção de Volume & $\begin{array}{l}10-35 \% \text { durante a época chuvosa, } 65-100 \% \text { durante a } \\
\text { época seca }\end{array}$ & Nenhuma \\
\hline Mitigação da Vazão de Pico & Redução dos picos de escoamento de chuvas intensas & Nenhuma \\
\hline Mitigação da Temperatura & Todas as Chuvas & Nenhuma \\
\hline $\begin{array}{l}\text { Melhoria da Qualidade da } \\
\text { Água }\end{array}$ & $\begin{array}{l}\text { Retém a deposição atmosférica e retarda a degradação } \\
\text { dos materiais que compõem o telhado, menores volu- } \\
\text { mes, menor arreamento de poluentes }\end{array}$ & Não \\
\hline Qualidade do Ar & $\begin{array}{l}\text { Filtra o ar, previne o aumento da temperatura, armaze- } \\
\text { na carbono }\end{array}$ & Nenhuma \\
\hline Conservação de Energia & $\begin{array}{l}\text { Isolamento das construções, redução dos impactos das } \\
\text { Ilhas de Calor Urbanas }\end{array}$ & Nenhuma \\
\hline Vegetação & $\begin{array}{l}\text { Permite evapotranspiração sazonal, promove a fotos- } \\
\text { síntese, o oxigênio, o balanço carbono hídrico }\end{array}$ & Nenhuma \\
\hline Espaço Verde & $\begin{array}{l}\text { Realoca espaços verdes perdidos com as } \\
\text { edificações, no entanto não equivalente a uma floresta }\end{array}$ & Nenhuma \\
\hline $\begin{array}{l}\text { Bônus no Zoneamento de } \\
\text { Área de Piso }\end{array}$ & $\begin{array}{l}3 \mathrm{ft} 2(0,3 \mathrm{~m} 2) \text { de coeficiente de área de pavimento } \\
\text { adicional para cada ft } 2 \\
\left(0,09 \mathrm{~m}^{2}\right) \text { de Telhado Ecológico quando a construção } \\
\text { cobrir mais de } 60 \%\end{array}$ & Nenhuma \\
\hline $\begin{array}{l}\text { Redução das Taxas de } \\
\text { Drenagem Urbana }\end{array}$ & Pode chegar a $45 \%$ & Nenhuma \\
\hline $\begin{array}{l}\text { Aprovado como medida de } \\
\text { Gestão de Água de Chuva }\end{array}$ & Para todas as necessidades atuais das cidades & Não \\
\hline Habitat & Para insetos e pássaros & Nenhuma \\
\hline Habitabilidade & $\begin{array}{l}\text { Amortece ruídos, elimina luzes ofuscantes, alternativa } \\
\text { estética, oferece recreação passiva }\end{array}$ & Nenhuma \\
\hline
\end{tabular}




\begin{tabular}{|c|c|c|}
\hline Custos & $\begin{array}{l}\text { Altamente variável entre } 54-130 \text { US\$/ } / \mathrm{m}^{2} \text { para novas } \\
\text { construções, e } 75-215 \text { US\$/ } / \mathrm{m}^{2} \text { para reforma }\end{array}$ & $\begin{array}{l}\text { Altamente va- } \\
\text { riável entre } \\
\text { 22-107 US\$/ } \\
\text { m² para no- } \text { vas } \\
\text { contruções, e } \\
43-161 \\
\text { US\$/m² para } \\
\text { reforma }\end{array}$ \\
\hline Custos Compensáveis & $\begin{array}{l}\text { Redução dos equipamentos de água de chuva, econo- } \\
\text { mia de energia, aumento do valor do aluguel e da pro- } \\
\text { priedade, redução da necessidade do uso de materiais } \\
\text { isolantes, redução do volume de esgoto, } \\
\text { criação de indústrias e empregos }\end{array}$ & Nenhuma \\
\hline Durabilidade & $\begin{array}{l}\text { Membrana impermeável protegida da ação } \\
\text { da temperatura e da exposição solar dura mais de } 36 \\
\text { anos }\end{array}$ & $\begin{array}{l}\text { Pouca prote- } \\
\text { ção, exposi- } \\
\text { ção } \\
\text { aos elemen- } \\
\text { tos, dura } \\
\text { menos } \\
\text { de } 20 \text { anos }\end{array}$ \\
\hline
\end{tabular}

Fonte: (Liptan e Strecker (SD), 2007)

Verificou-se no site da Empresa Ecodhome um exemplo de telhado verde como seus custos e materiais.

Figura 1 - Estrutura de madeira

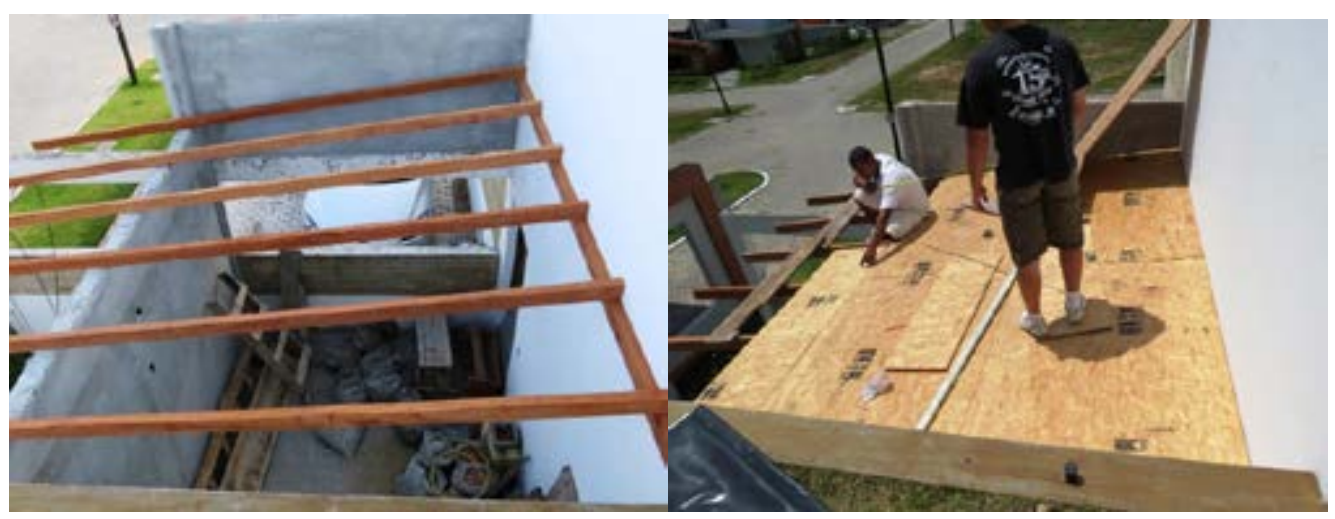

Fonte: (Empresa Ecodhome, 2018)
Figura 2 - Base de OSB

Fonte: (Empresa Ecodhome, 2018) 
Figura 3 - Lona impermeabilizante Figura 4 - Manta geotêxtil

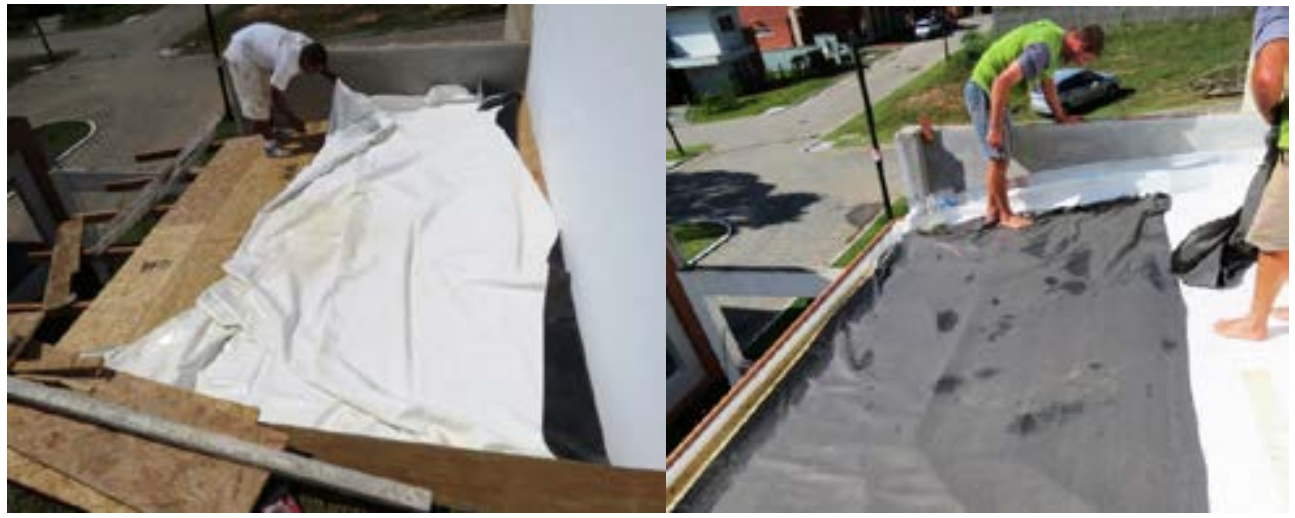

Fonte: (Empresa Ecodhome, 2018) Fonte: (Empresa Ecodhome, 2018)

Figura 5 - Argila expandida

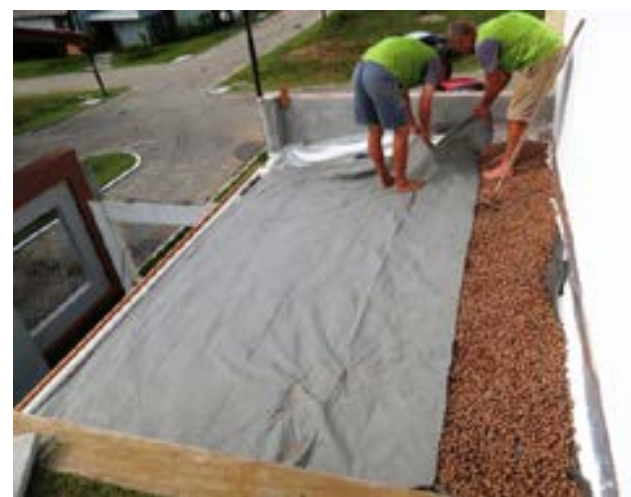

Fonte: (Empresa Ecodhome, 2018)
Figura 6 - Terra adubada

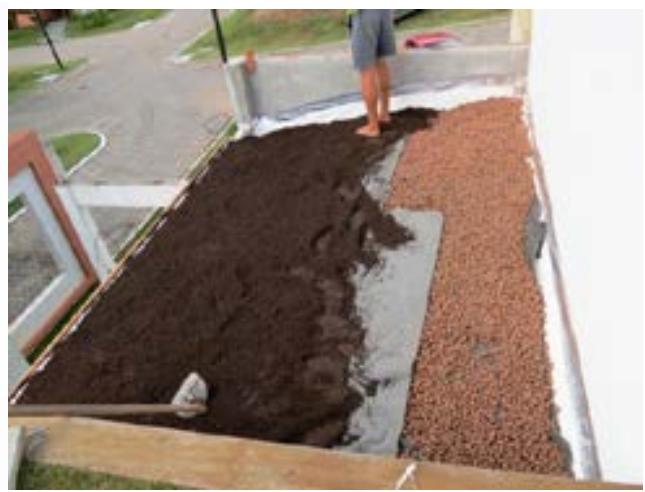

Fonte: (Empresa Ecodhome, 2018)
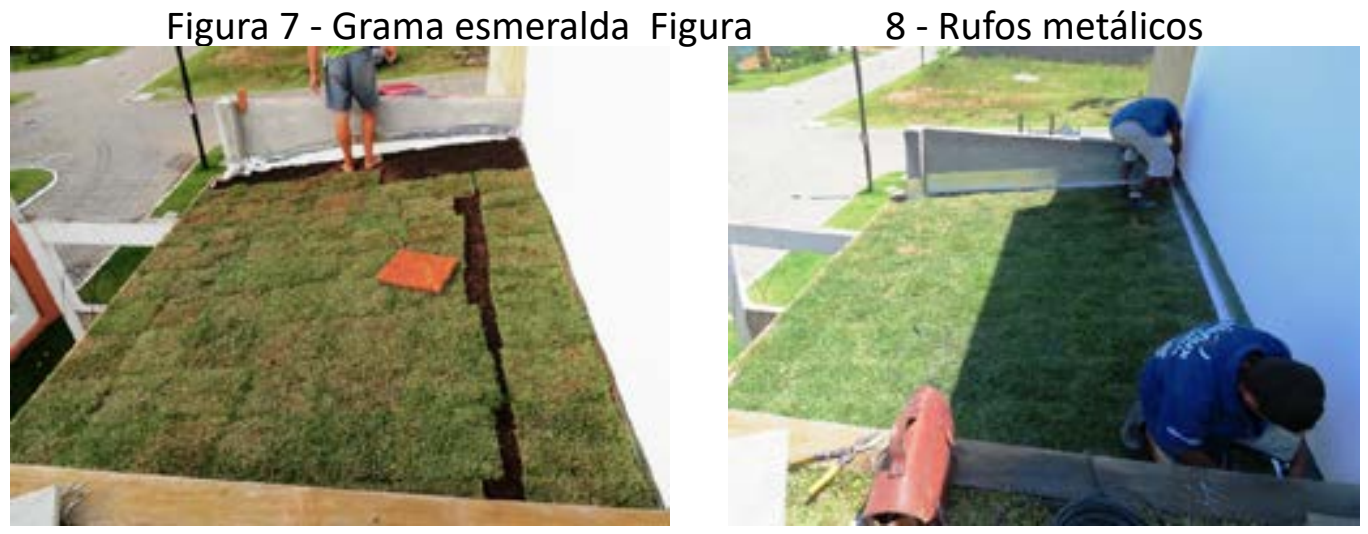
A seguir serão relacionados os materiais necessários para construir o telhado verde mostrado acima.

Tabela 2 - Custos para executar esta cobertura de 12 metros quadrados já impermeabilizada:

\begin{tabular}{|l|l|}
\hline Material & Custo/ tempo \\
\hline Manta geotêxtil da marca Bidim & $\mathrm{R} \$ 60,00$ \\
\hline Argila Expandida & $\mathrm{R} \$ 150,00$ \\
\hline Argila Expandida & $\mathrm{R} \$ 150,00$ \\
\hline Terra adubada & $\mathrm{R} \$ 70,00$ \\
\hline Grama & $\mathrm{R} \$ 100,00$ \\
\hline Rufo metálico & $\mathrm{R} \$ 250,00$ \\
\hline Mão-de-obra & $\mathrm{R} \$ 150,00$ \\
\hline & $\mathrm{R} \$ 780,00$, ou seja, \\
\hline Total & $\mathrm{R} \$ 65,00$ por metro quadrado \\
\hline Tempo de execução & 2 horas \\
\hline
\end{tabular}

Fonte: (Empresa Ecodhome)

Após uma pesquisa realizada em cinco lojas de matérias de construção, foi coletada uma média de preços de materiais de construção de um telhado convencional feito com telha de fibrocimento, para o mesmo local feito com telhado verde. Obteve-se o seguinte resultado:

Tabela 3 - Custos para executar esta cobertura de 12 metros quadrados convencional feito com telha de fibrocimento:

\begin{tabular}{|l|l|c|}
\hline Material & Valor unitário & Quantidade \\
\hline $\begin{array}{l}\text { Telha de fibrocimento ondulada } 2,13 \times 1,10 \\
\mathrm{~m}\end{array}$ & $\mathrm{R} \$ 50,00$ & 6 \\
\hline Viga pinus $10 \mathrm{~cm} \times 4,5 \mathrm{~cm} \times 3,96 \mathrm{~m}$ & $\mathrm{R} \$ 30,00$ & 6 \\
\hline Prego para telheiro $18 \times 30$ saco com $1 / 2 \mathrm{~kg}$ & $\mathrm{R} \$ 14,90$ & 1 \\
\hline Mão-de-obra & $\mathrm{R} \$ 200,00$ & \\
\hline
\end{tabular}




\begin{tabular}{|l|l|l|}
\hline Total & R\$ 694,90 & \\
\hline Tempo de execução & 2 horas & \\
\hline
\end{tabular}

Fonte: (Próprio autor, 2019)

\section{DISCUSSÃO}

Analisou-se que, com esses estudos fica evidente que a utilização do telhado verde contribui para um melhor controle térmico interior e consequente redução do consumo de energia. $O$ desempenho superior desse se comparado com os telhados de fibrocimento e com os cerâmicos deve-se às suas características construtivas. Fazse necessário ter em mente que é possível melhorar o desempenho dos telhados convencionais, por exemplo, pode-se fazer um telhado convencional de dois níveis e dificultar a transmissão de calor e/ou pintar o telhado de branco a fim de diminuir a absorção da luz solar. Porém, a natureza do próprio telhado verde é mais simples de ser seguida devido à vegetação e ao solo agirem como isolantes térmicos naturais. Além do fato de ser uma opção arquitetônica mais agradável, agrega valor para o imóvel, podese cultivar, admirar um jardim ou pisar diretamente na vegetação (desde que concebida para essa finalidade).

Verificou-se que ele tem vários benefícios decorrentes da adoção em áreas urbanas em relação aos telhados convencionais, tais como: qualidade da água, qualidade do ar, vegetação, espaço verde, conservação de energia, habitabilidade, redução das Taxas de Drenagem Urbanas e durabilidade, enquanto os telhados convencionais não proporcionam quaisquer desses benefícios.

Observou-se que o custo para se construir um telhado verde ainda é maior do que o convencional, entretanto esse valor vem diminuindo anualmente, pois pesquisas mais antigas mostram uma diferença de custo maior comparando com as atuais.

\section{CONSIDERAÇÕES FINAIS}

O telhado verde possui grande potencial de utilização. Numa cidade como o Rio 
de Janeiro, onde há um verão com noites quentes, a sua aplicação pode, se não evitar, reduzir o uso de equipamentos de ventilação ou de ar-condicionado.

Sua limitação ainda está na falta de conhecimento do grande público, salienta-se que é mais interessante economicamente para o dono do imóvel instalá-lo numa edificação que está sendo construída do que em adaptá-lo em uma existente, além disso, a favelização, é um óbice ao seu uso mais difuso, pois é sabido que o furto de energia é uma infeliz rotina, assim perdendo o seu principal atrativo, isto é, a economia de energia.

Este artigo não abordou especificamente o quantitativo de energia economizada em valores absolutos, seu foco foi descobrir se o telhado verde seria eficaz em reduzir a temperatura ambiente interna em edificações. Trabalhos futuros poderão trazer estimativas de economia numeráveis, por exemplo, em quilowatt-hora/mês que foram deixados de ser gasto com ventilação ou com arcondicionado além de mostrar a evolução de suas aplicações no Brasil e no mundo.

O telhado verde, conforme estudado, pretende aliar eficiência energética, compromisso com o meio-ambiente e técnicas paisagísticas para ser uma boa opção para as residências brasileiras.

Verificou-se que o seu valor ainda é maior do que o convencional. As soluções para esse problema seriam a criação de novas tecnologias e métodos que possam diminuir seu preço. Além disso, os governantes poderiam contribuir com ações e incentivos, como a redução do IPTU e/ ou da tarifa de conta de luz, para quem construí-lo, como forma de incentivar o seu emprego.

\section{REFERÊNCIAS}

ARAÚJO, S. As funções dos Telhados Verdes no Meio Urbano, na Gestão e no Planejamento de Recursos Hídricos. Dissertação apresentada ao Instituto de Florestas da Federal Rural do Rio de Janeiro, Rio de Janeiro, 2007. 
ARQUITETURA E SUSTENTABILIDADE. Telhado Verde - Tipos e Implantação. Disponível em: <http://arquiteturaesustentabilidade.com/2012/10/01/telhado-verde-tipos-e-implementacao/>. Acesso em: 20 nov. 2013.

BALDESSAR, S. Telhado Verde e sua Contribuição na Redução da Vazão da ÁGUA Pluvial Escoada. Dissertação (Mestrado) - Universidade Federal do Paraná, Setor de Tecnologia, Programa de Pós-Graduação em Engenharia de Construção Civil de Curitiba, Curitiba, 2012.

BASS, B et. Al.Mitigating the urban heat Island with Green Roof Infraestructure. Departament of Earth and Oceans Sciences. University of Bristish Columbia. 2000.

Disponível em: http://w.w.w.clenairpartnership.org/cooltoronto/pdf/finalpaper_bass. pdf Acesso em 10 out. 2006.

BENETTI PAISAGISMO. Telhado Verde. Disponível em: <HTTP://www.benettipaisagismo. com.br/telhado-verde/benetti-paisagismo.php>. Acesso em: 20 jan 2019.

BIANCHINI, F.; HEWAGE, K. How "green" are the green roofs? Lifecycle analysis of green roof materials. Building and Environment,v. 48, p.57-65, 2012.

CANERO, R. F. e REDONDO, P. G. Green Roof as a Habitat for Birds: A Review. Journal of Animal and Veterinay Advances, n. 15, p. 2041-2052. 2010.

CARNEIRO, T.; GUISELINI, C.; PANDORFI, H.; NETO, J.; LOGES, V.; SOUZA, R. Condicionamento térmico primário de instalações rurais por meio de diferentes tipos de cobertura. Revista Brasileira de Engenharia Agrícola e Ambiental. V.19, n.11, p.1086 - 1062, 2015.

COSTA, B. S.; COELHO, G. T. F.; PEREIRA, D. R. Estudo da influência do Telhado Verde, como material empregado em construção, sobre a temperatura. Artigo apresentado no 
Congresso Técnico Científico da Engenharia e da Agronomia - CONTECC' 201515 a 18 de setembro de 2015, Fortaleza, 2015.

D'AVILA, M.R; PERALTA, Ê; S.; FRITSCHER, J. P. C. Cobertura Vegetal: desenvolvimento e produção da tecnologia Telhado Vivo. - Congresso internacional sustentabilidade e habitação de interesse social. Porto Alegre, 04 a 07 de maio de 2010.

ECOCIDADES. Telhado verde: os jardins da Babilônia continuam funcionais. Disponível em: https://www.oecocidades.com/telhado-verde-os-jardins-da-babilonia-continuam-funcionais/>. Acesso em: 29 maio 2019.

ECODHOME. Arquitetura e Consultoria. Disponível em <http://www.ecodhome.com. br/blog/category/eficiencia-energetica/> Acesso em: 10 dezembro 2017.

ECOEFICIENTES. O que é e como fazer um telhado verde. Disponível em: <http://www. ecoeficientes.com.br/o-que-e-e-como-fazer-um-telhado-verde/>. Acesso em: $01 \mathrm{mar}$ 2016.

ECOTELHADO. Nova Iorque terá o maior Telhado Verde do Mundo. Disponível em: <http://ecotelhado.com/nova-iorque-tera-o-maior-telhado-verde-do-mundo/>. Acesso em: 20 fev. 2019.

FERREIRA, C. A.; MORUZZI, R. B. Considerações sobre a aplicação do Telhado Verde para captação de água de chuva em sistemas de aproveitamento para fins não potáveis. Instituto de Geociências e Ciências Exatas (IGCE). Universidade Estadual Paulista. Campus Rio Claro, SP. 2007.

HENEINE, M. C. A. de S. Cobertura Verde. Monografia (Especialização em Tecnologia e produtividade das construções) - escola de Engenharia, Universidade Federal de Minas Gerais, Belo Horizonte, 2008 Imagem estrutura do telhado verde. Disponível em <http:// arqout.blogspot.com.br/2014/04/jardins-em-cobertura-telhados-verdes-i.html>. Acesso em: 24 de fevereiro de 2019. 
KOSAREO, L.; RIES, R. Comparative environmental life cycle assessment of green roofs. Building and Environment,v. 42, n. 7, p.2606-2613, 2007.

LOPES, D. A. R. Avaliação do Comportamento Térmico de Coberturas Verdes Leves (CVLs) aplicadas aos Climas Tropicais. 2007. Dissertação (Mestrado em Ciências da Engenharia Ambiental) - Universidade de São Carlos, São Carlos, 2007.

NIACHOU, A. et al. Analysis of green roof thermal properties and investigation of its energy performance. Energy and Buildings, v. 33, n. 7, p. 719-729, 2001.

OLIVEIRA, E.W.N. Telhados Verdes para habitações de interesse social: retenção das águas pluviais e conforto térmico. 2009. 87 f. Dissertação (Mestrado em Ciências) Centro de Tecnologia e Ciências, Universidade do Estado do Rio de Janeiro. Rio de Janeiro. 2009.

PENSAMENTO VERDE. Quais as vantagens e desvantagens do telhado verde? Disponível em: <http://www.pensamentoverde.com.br/arquitetura-verde/quais-as-vantagens-e-desvantagens-do-telhado-verde/>. Acesso em: 20 set. 2013.

RIVERO, R. Arquitetura e clima: acondicionamento térmico natural. Porto Alegre: D. C. Luzzatto Editores: Ed. da Universidade, UFRGS, 1998.

SAIZ, S.; KENNEDY, C.; BASS, B.; PRESSNALL, K. Comparative Life Cycle Assessment of Standard and Green Roofs. Environmental Science \& Technology, v. 40, n. 13, p.43124316, 2006.

STRAPASSON, D. C.; FREITAS, M. do C. D.; SANTOS, A. dos. Estudo Comparativo do Consumo Energético do Telhado Convencional e Verde Leve em uma edificação - 5o encontro de engenharia e tecnologia dos Campos Gerais, 2010.

TOMAZ, 2008. Cobertura Verde. 2008. In: Curso de manuseio de águas pluviais. Capítulo 
51.

WILLES, J. A., Tecnologias em telhados verdes extensivos: meios de cultura, caracterização hidrológica e sustentabilidade do sistema. Escola Superior de Agricultura Luiz de Queiroz-USP, dez. 2014. Disponível em: <http://www.teses.usp.br/teses/disponiveis/11/11136/tde-03122014-171411/pt-br.php>. Acesso em: 15 fev 2019. 